\title{
Gebelikte Kullanılan Sigara Dozunun Maternal ve Fetal Sonuçlar ile İlişkisi
}

\author{
Relationship Between Smoking Doses and Maternal and Fetal Outcomes of Pregnancy
}

\author{
Çiğdem Yayla ABİDE ${ }^{1}$, Ebru ÇOĞENDEZ ${ }^{1}$ \\ Pınar KUMRU ${ }^{1}$, Evrim Bostancı ERGEN ${ }^{1}$, Çetin KILIÇÇI ${ }^{1}$
}

1. Zeynep Kamil Kadın ve Çocuk Hastalıkları Eğitim ve Araştırma Hastanesi, Kadın Hastalıkları ve Doğum Bölümü, İstanbul, Türkiye

\section{$\ddot{O Z E T}$}

Amaç: Sigaranın maternal, fetal ve neonatal olumsuz etkileri bilinmektedir. Biz bu çalışmada sigaranın günlük kullanım miktart ile maternal ve perinatal sonuçlar arasındaki ilişkiyi araştırmayı amaçladık.

Gereçler ve Yöntem: Bu çalışma 2015 - 2017 yılları arasında Zeynep Kamil Kadın ve Çocuk Hastalıkları Eğitim ve Araştırma Hastanesi Kadın Hastalıkları ve Doğum Kliniğinde yapılmiştır. Çalışmaya 1029 sigara içmeyen ve 261 sigara içen gebe dahil edildi. Hastalar gebelik boyunca içtikleri sigara adedine göre hafif, orta ve ă̆ır içici olmak üzere sub-gruplara ( $\leq 5$ adet /gün, 5-15 adet/gün, >15 adet/gün) ayrlldl. Hastalartn demografik özellikleri kaydedildi. Tüm gebelerde maternal ve perinatal sonuçlar değerlendirildi.

Bulgular: Sigara içen gebelerin \%28.4' ü günde $\leq 5$ adet sigara, \%62.5' $i$ 5-15 adet sigara ve \%9.2 si >15 adet sigara içmekte idi. Yenidoğanın doğum haftası, doğum ă̆ırlığı, boyu, 1. Dakika apgar skoru ve 5. Dakika apgar skoru sigara içen gebeler lehine istatistiksel olarak anlamlı oranda düşük bulundu. Sigara içen gebelerin yenidoğanlarının doğum ă̆lrlı̆̆l sigara içmeyen gebelere göre 162 gram daha düşük bulundu $(p<0.0001)$. Gebelerin doğum şekli ve bebeklerin cinsiyetleri açısından gruplar arasında anlamlı fark bulunmadı. Sigara içen gebelerde preeklampsi, erken membran rüptürü (EMR), preterm prematür membran ruptürü (PPROM), fetal gelişme kisitlılığ $(F G R)$, intrauterin fetal kayıp ve yenidoğan yoğum bakım ünitesine yatış oranları sigara içmeyen gebelere göre istatistiksel anlamda daha fazla saptand. Subgruplar kendi arasında karşılaștırıldığında ise >15 adet/gün sigara kullanan gebelerde diğerlerine göre istatistiksel anlamda daha düşük doğum ă̆ırlı̆̆ ve daha yüksek yenidoğan yoğun bakım ünitesine yatış oranı görülmüştür.

Sonuç: Çalışmamız, gebelikte maternal sigara kullanımının doza bağlı bir şekilde düşük doğum ă̆ırlığl ve yenidoğan yoğun bakım ünitesine yatış riskini artırdığııı göstermiştir.

Anahtar Kelimeler: gebelik, sigara, maternal prognoz, fetal prognoz

\section{ABSTRACT}

Objective: We aimed to investigate the relationship between daily smoking doses and maternal and perinatal outcomes.

Material and Methods: This study was conducted between 2015 and 2017 in Zeynep Kamil Women's and Children's Hospital Education and Research Hospital. 1029 pregnancies who did not smoke and 261 pregnancies who smoked were included in the study. Patients were divided into subgroups ( $\leq 5 \mathrm{pcs} /$ day, 5-15 pcs / day,> 15 pcs / day), which were mild, moderate and heavy smokers. Demographic characteristics of the patients were recorded. All maternal and perinatal outcomes were evaluated.

\section{İletişim Bilgileri}

Sorumlu Yazar: Çiğdem Yayla ABIDE

Yazışma Adresi: Zeynep Kamil Mahallesi, Dr Burhanettin Üstünel Sokağı, No:10, Üsküdar, İstanbul, Türkiye

E-posta: cigdemabide@gmail.com

Tel: +90 (506) 6015600

Makale Geliş Tarihi: 11.02.2018

Makale Kabul Tarihi: 13.02.2018

DOI: http://dx.doi.org/10.16948/zktipb.393346
Results: $28.4 \%$ of the smokers were using $\leq 5$ cigarettes per day, $62.5 \%$ of the smokers were using 5-15 cigarettes and 9.2\% of the smokers were using > 15 cigarettes. Birth weight, gestational week of birth, birth height, 1st minute apgar scores and 5th minute apgar scores were statistically significantly lower in pregnancies who smoked. The birth weight of smokers was 162 grams lower than pregnancies who did not smoke $(p<0.0001)$. There was no significant difference between the groups regards to type of delivery and the sex of the infants. Rates of preeclampsia, premature rupture of membranes (PPROM), fetal growth restriction (IUGR), intrauterine fetal demise and neonatal care unit admission were statistically significantly higher in pregnancies who smoked. When subgroups were compared, pregnancies who smoked > 15 cigarettes per day were found to have statistically significantly lower birth weight and higher rates of neonatal intensive care unit admission.

Conclusion: Our study revealed that the risk of low birth weight and risk of admission to the neonatal intensive care unit increased with increasing cigarette usage during pregnancy.

Keywords: pregnancy, cigarette, maternal prognosis

\section{GíRiș}

Gebelikte sigara içilmesi, gerek anne sağlı̆̆ 1 üzerine olumsuz etkileri gerekse sağlıklı nesillerin yetişmesi açısından önemli ve önlenebilir bir sağlik problemidir. Amerikan Kadın Hastalıkları ve Doğum Uzmanları sigarayı bırakma stratejilerinin her gebe kadın için rutin prenatal bakıma entegre edilmesini önermektedirler (1). Türkiye'de yapılan çalışmalarda gebe kadınların gebelikte sigara içme oranı \%6,8-\%28 arasında değişmektedir (2).

Sigaranın içinde bulunan toksik maddelerden en önemlisi olarak belirtilen nikotin ve karbonmonoksitin gebelik sürecini olumsuz etkilediği bildirilmiştir. Sigara içildiğinde nikotin akciğerlerden dolaşıma hızla girmekte ve etkisi çok çabuk başlamaktadır. Nikotin bütün vücuda yayılır ve dokularda birikir. Sigarada bulunan zararlı maddeler gebelerde plasentadan fetal dolaşıma kolayca geçmektedir (3). Sigara dumanındaki karbonmonoksit, içilen paket başına kandaki karboksihemoglobin düzeyini \%4-5 oranında artırmaktadır. Karbonmonoksit kandaki oksijene güçlü bir şekilde bağlanarak, alyuvarların fetüse oksijen taşımasına engel olur. Bunun sonucunda sigara içen gebelerin fetüslerinde hipoksi düzeyi artar.

Gebelikte aktif sigara içimi ektopik gebelik (4), abortus (5), plasenta previa (6), dekolman plasenta (6) preterm doğum (7), düşük doğum ağırlığ 1 (7), ölü doğum (8) için artmış risk teşkil etmektedir. Dünyaya gelen çocuk açısından baktığımızda fetüsün doğum öncesi sigaraya uzun süreli maruziyeti 
çocuklarda solunum yolu rahatsızlıkları (9), kardiyovasküler hastalık (10), obezite (11) ve fertilite problemleri (12) için risk oluşturmaktadır.

Biz bu çalışmada, gebelikte günlük içilen sigara miktarı ile maternal ve fetal gebelik sonuçları arasındaki ilişkiyi değerlendirmeyi amaçladık.

\section{GEREÇLER ve YÖNTEM}

Bu çalışma 2015 - 2017 yılları arasında Zeynep Kamil Kadın ve Çocuk Hastalıkları Eğitim ve Araştırma Hastanesi Kadın Hastalıkları ve Doğum Kliniğine başvuran 1029 sigara içmeyen ve 261 sigara içen gebe ile yapılmıştır. Tüm hamileliği boyunca sigara kullanan kadınlar çalışmaya dahil edilirken; astım bronşiale vb solunum sistemi hastalıkları, kardiovasküler hastalık, tiroid hastalığı olan gebeler, çoğul gebelikler, konjenital anomalili olgular çalışma dışı bırakıldı. Çalışma protokolü lokal etik kurul tarafindan onaylandı. Çalışmaya katılan tüm gebelerden yazılı bilgilendirilmiş onam alındı. Gestasyonel yaş son adet tarihine ve erken gebelik ultrason taramasina göre belirlendi.

Maternal tanımlayıcı özelliklerden yaş, gravida, parite, yaşayan çocuk ve abortus sayıları, vücut kitle indeksi (BMI) ve içilen günlük sigara adeti kaydedildi. Hastalar gebelikte içtikleri günlük sigara adedine göre sub-gruplara ( $\leq 5$ adet sigara /gün, 5-15 adet sigara gün, $>15$ adet/gün) ayrıld1. $\leq 5$ adet sigara /gün içen gebeler hafif içici; 5-15 adet sigara gün içen gebeler orta içici; >15 adet/gün içen gebeler ağır içici olarak adlandırıldı.

Tüm gebelerde maternal ve perinatal sonuçlar değerlendirildi. Preeklampsi, gestasyonel diabet (GDM), kolestaz, invazyon anomalisi, plasenta previa, dekolman plasenta, atoni, erken doğum tehtidi (EDT), erken membran rüptürü(EMR), membranların prematür rüptürü (PPROM), oligohidromnios, polihidroamnios, gün aşımı, düşük doğum ağırlığ1, fetal gelişme kısıtlılığı, intrauterin ölüm, yenidoğan yoğun bakım ünitesine yatış oranları sigara içen ve içmeyen gruplar arasında karşılaştırıldığı gibi; bu komplikasyonların günlük içilen sigara adeti ile ilişkisi de karşılaştırıldı. Gruplar doğum şekli açısından sigara içen ve içmeyenler olmak üzere karşılaştırıld1.

Doğum sonrası yenidoğanın gebelik haftası, apgar skorları, doğum ağırlığı, boy ve baş çevresi, cinsiyet, yenidoğan yoğun bakım ünitesine kabul sıklı̆̆1 sigara içen ve içmeyen gruplar arasında karşılaştırıldı. Çalışmamızdaki tüm yenidoğanlar bebek hemşiresi tarafından aynı elektronik ölçekte tartıldı.

\section{İstatistiksel analiz}

İstatistiksel Analizler SPSS 17.0 (The Statistical Package for the Social Sciences, SPSS Inc., version 17; Chicago, IL, USA) yazılımı kullanılarak yapıld1. Tanımlayıcı istatistikler ortalama \pm standart sapma ve oran değerleri olarak verildi. Değişkenlerin normal dağılıma uygunluğu görsel (histogram ve olasılık grafikleri) ve analitik yöntemlerle (Kolmogorov-Smirnov) incelendi.
Niceliksel verilerin karşılaştırılmasında normal dağllım gösteren parametrelerin ikili gruplar olarak karşılaştırılmasında ise bağımsız örneklem t testi ve normal dağılım göstermeyen parametrelerin ikili gruplar arası karşılaştırmalarında Mann-Whitney U testi kullanılarak karşılaştırıldı.

Niteliksel verilerin karşılaştırılmasında ise Ki-Kare testi veya test koşulları sağlanamadığı durumlarda Fisher's Exact Ki-Kare testi kullanıldı. Sonuçlar p değerinin 0.05 'in altında olduğunda anlamlı olduğu şeklinde değerlendirildi.

\section{BULGULAR}

Çalışmaya 261 sigara içen ve 1029 sigara içmeyen gebe dahil edildi. Sigara içen gebelerin \%28.4' ü (n:74) hafif içici, \%62.5'i (n:163) orta içici ve \%9.2'si (n:24) ağır içiciydi. Sigara içen gebelerin ortalama yaşı $31,43 \pm 5,42$, sigara içmeyen gebelerin ortalama yașı $31,79 \pm 5,13$ idi $(p<0.05)$. Gruplar arasında gravida, parite ve BMI açısından istatistiksel anlamlı farklılık yoktu. Abortus oranı sigara içen olgularda içmeyenlere göre anlamlı oranda yüksek bulundu $(\mathrm{p}<0.05)$ (Tablo 1).

\begin{tabular}{|c|c|c|c|}
\hline & $\begin{array}{c}\text { Sigara içen grup } \\
(\mathrm{N}: 261)\end{array}$ & $\begin{array}{l}\text { Sigara içmeyen } \\
\text { grup (N:1029) }\end{array}$ & $\begin{array}{c}P \\
\text { değeri }\end{array}$ \\
\hline Yaş (yıl) & $31,43 \pm 5,42$ & $31,79 \pm 5,13$ & 0,324 \\
\hline VKi $\left(\mathrm{kg} / \mathrm{m}^{2}\right)$ & $24,77 \pm 4,62$ & $26,14 \pm 6,59$ & 0,817 \\
\hline Gravida & $4,18 \pm 1,24$ & $3,98 \pm 1,22$ & 0,484 \\
\hline Parite & $1,69 \pm 0,73$ & $1,5 \pm 0,79$ & 0,072 \\
\hline Yaşayan & $1,55 \pm 0,76$ & $1,38 \pm 0,75$ & $0,024 *$ \\
\hline Abortus & $1,59 \pm 0,89$ & $1,46 \pm 0,95$ & $0,020 *$ \\
\hline \multicolumn{4}{|c|}{ Sigara Kullanım Adedi } \\
\hline$\leq 5$ adet/gün & $74(\% 28,4)$ & & \\
\hline 5-15 adet/gün & $163(\% 62,5)$ & & \\
\hline >15 adet/gün & $24(\% 9,2)$ & & \\
\hline
\end{tabular}

Gebelikte aktif sigara içen ve içmeyen iki grup arasinda; doğum şekli, primer sezaryen oranı ve fetal distres nedeniyle sezaryen oranı açısından istatistiksel olarak anlamlı farklılık saptanmadı $(\mathrm{p}>0.05)$ (Tablo 2).

Sigara içen grupta doğum haftas $38,32 \pm 1.45$, içmeyen olgularda $38,78 \pm 1.48$ olup bu fark istatistiksel olarak anlamlı idi $(\mathrm{p}<0.0001)$. Yenidoğanın doğum ağırlığ1 sigara içen grupta $3186 \pm 464,94$ gram, sigara içmeyen grupta $3348,65 \pm 441,95$ gram bulundu. 162 gramlik bu fark istatistiksel olarak anlamlı idi $(\mathrm{p}<0.0001)$.

Yenidoğanın boyu sigara içen grupta içmeyen olguların yenidoğanlarından istatistiksel anlamda daha kısa bulundu $(p<0.0001)$. Sigara içen grupta yenidoğanın 1. ve 5. Dakika apgar skoru sigara içmeyen olgulardan istatistiksel anlamda daha düşük bulundu. (sırasiyla $p<0.0001, p<0.005$ ). Cinsiyet açısından gruplar karşılaştırıldığında; sigara içen ve içmeyen gebelerin yenidoğanları arasında istatistiksel açıdan anlamlı farklılık saptanmadı (Tablo 3). 
Tablo 2: Doğum ile ilgili tanımlayıcı sonuçlar.

\begin{tabular}{|c|c|c|c|}
\hline & $\begin{array}{l}\text { Sigara } \\
\text { içen grup } \\
(\mathrm{N}: 261)\end{array}$ & $\begin{array}{l}\text { Sigara içme- } \\
\text { yen grup } \\
(\mathrm{N}: 1029)\end{array}$ & P değeri \\
\hline \multicolumn{4}{|l|}{ Doğum Şekli } \\
\hline NSD & $137(\% 52,5)$ & $532(\% 51,7)$ & \multirow{2}{*}{0,820} \\
\hline Sezaryen & $124(\% 47,5)$ & $497(\% 48,3)$ & \\
\hline $\begin{array}{l}\text { Primer } \\
\text { sezaryen }\end{array}$ & $51(\% 19,5)$ & $199(\% 19,3)$ & 0,941 \\
\hline $\begin{array}{l}\text { Fetal distress nedeniyle } \\
\text { sezaryen }\end{array}$ & $19(\% 7,3)$ & $58(\% 5,6)$ & 0,317 \\
\hline $\begin{array}{l}\text { Doğum Öncesi } \\
\text { Hematokrit }\end{array}$ & $35,09 \pm 4,75$ & $35,62 \pm 4,24$ & 0,078 \\
\hline $\begin{array}{l}\text { Doğum Sonrası } \\
\text { Hematokrit }\end{array}$ & $32,06 \pm 4,09$ & $32,36 \pm 4,09$ & 0,517 \\
\hline $\begin{array}{l}\text { HCT arasındaki } \\
\text { fark }\end{array}$ & $3,04 \pm 4,44$ & $3,26 \pm 3,59$ & 0,463 \\
\hline
\end{tabular}

NSD: Normal spontan doğum, ${ }^{*} \boldsymbol{p}$ values of less than 0,05 was considered statistically significant.

Tablo 3: Yenidoğana ait tanımlayıcı özellikler.

\begin{tabular}{|l|c|c|c|}
\hline & $\begin{array}{c}\text { Sigara } \\
\text { içen grup } \\
\text { (N:261) }\end{array}$ & $\begin{array}{c}\text { Sigara içmeyen } \\
\text { grup (N:1029) }\end{array}$ & P değeri \\
\hline Doğum Haftası (hafta) & $38,32 \pm 1,45$ & $38,78 \pm 1,48$ & $0,0001^{*}$ \\
\hline Doğum Ağırlığ (gram) & $3186 \pm 464,94$ & $3348,65 \pm 441,95$ & $0,0001^{*}$ \\
\hline Yenidoğan Boy (cm) & $40,31 \pm 1,66$ & $49,63 \pm 2,01$ & $0,0001^{*}$ \\
\hline Baş Çevresi (cm) & $34,49 \pm 2,70$ & $34,50 \pm 1,98$ & 0,168 \\
\hline 1. dk Apgar & $7,90 \pm 0,53$ & $7,97 \pm 0,65$ & $0,0001^{*}$ \\
\hline 5. dk Apgar & $9,06 \pm 0,28$ & $9,10 \pm 1,11$ & $0,005^{*}$ \\
\hline Cinsiyet & & & \multirow{2}{*nnn}{ Kız } \\
\cline { 1 - 3 } Erkek & $134(\% 51,3)$ & $502(\% 48,8)$ & 0,418 \\
\hline
\end{tabular}

* $\boldsymbol{p}$ values of less than 0,05 was considered statistically significant.

Tablo 4: Maternal ve Perinatal Outcome.

\begin{tabular}{|c|c|c|c|}
\hline & $\begin{array}{l}\text { Sigara içen } \\
\text { grup (N:261) }\end{array}$ & $\begin{array}{l}\text { Sigara içmeyen } \\
\text { grup (N:1029) }\end{array}$ & $P$ değeri \\
\hline Preeklampsi & $23(\% 8,4)$ & $39(\% 3,8)$ & $0,001^{*}$ \\
\hline GDM & $22(\% 8,4)$ & $73(\% 7,1)$ & 0,461 \\
\hline Kolestaz & $1(\% 0,4)$ & $12(\% 1,2)$ & 0,485 \\
\hline $\begin{array}{l}\text { Plasenta invazyon } \\
\text { anomalisi }\end{array}$ & $1(\% 0,4)$ & $2(\% 0,2)$ & 0,493 \\
\hline Plasenta Previa & $2(\% 0,8)$ & $18(\% 1,7)$ & 0,399 \\
\hline Atoni & $1(\% 0,4)$ & $2(\% 0,2)$ & 0,493 \\
\hline EDT & $17(\% 6,5)$ & $45(\% 4,4)$ & 0,149 \\
\hline EMR & $36(\% 13,8)$ & $50(\% 4,9)$ & $0,0001^{*}$ \\
\hline PPROM & $12(\% 4,6)$ & $4(\% 0,4)$ & $0,0001^{*}$ \\
\hline Oligohidramnios & $21(\% 8)$ & $63(\% 6,1)$ & 0,261 \\
\hline Polihidramnios & $7(\% 2,7)$ & $13(\% 1,3)$ & 0,154 \\
\hline Gün Aşımı & $13(\% 15)$ & $61(\% 6,1)$ & 0,484 \\
\hline Düşük Doğum Ağırlığı & $40(\% 15,3)$ & $36(\% 3,5)$ & $0,0001^{*}$ \\
\hline Fetal Gelişme Geriliği & $16(\% 6,1)$ & $10(\% 1)$ & $0,0001^{*}$ \\
\hline Dekolman Plasenta & $1(\% 0,4)$ & $4(\% 0,4)$ & 0,99 \\
\hline YDYBÜ Yatış & $26(\% 10)$ & $50(\% 4,9)$ & $0,002 *$ \\
\hline İntrauterin fetal kayıp & $8(\% 3,1)$ & $2(\% 0,2)$ & $0,0001^{*}$ \\
\hline
\end{tabular}

GDM: Gestasyonel diyabetes mellitus, EDT: Erken doğum tehditi, EMR: Erken membran ruptürü, PPROM: preterm prematur ruptur of membran, YDYBU: Yenidoğan yogun bakım ünitesi, * P: values of less than 0,05 was considered statistically significant.
Gebelikte sigara içimi ile preeklampsi, EMR, PPROM, düşük doğum ağırlığı, fetal gelişme kısıtlılı̆g1, intrauterin fetal kayıp ve yenidoğan yoğum bakım ünitesine yatış arasında istatistiksel anlamda ilișkili bulundu (Tablo 4). Bu maternal ve fetal komplikasyonlar gebelikte aktif sigara içen kadınlarda istatistiksel anlamda daha yüksek bulundu. $(\mathrm{p}<0.05)$

Sigara kullanım miktarı ile maternal ve fetal sonuçlar arasındaki ilişki Tablo 5' te gösterilmiştir. Sigara kullanım miktarı ile düşük doğum ağırlığ 1 ve yenidoğan yoğum bakım ünitesine yatış sıklığı arasında istatistiksel anlamda fark saptanmıştır. Ağır içicilerde düşük doğum ağırlığı $(p<0.0001)$ ve yenidoğan yoğum bakım ünitesine yatış sıklığ $(\mathrm{p}<0.005)$ hafif ve orta içicilere göre daha yüksek oranda bulundu. Ağır içicilerde EMR ve PPROM sıklığı hafif ve orta içicilere göre daha yüksek oranda görülmesine karşı bu fark istatistiksel olarak anlamlı bulunmadı (Tablo 5).

Tablo 5: Sigara kullanım adeti ile maternal ve fetal sonuçlar arasındaki ilişki.

\begin{tabular}{|c|c|c|c|c|}
\hline & $\begin{array}{l}\text { Sigara } \leq 5 \\
\text { adet/gün }\end{array}$ & $\begin{array}{l}\text { Sigara 5-15 } \\
\text { adet/gün }\end{array}$ & $\begin{array}{l}\text { Sigara }>15 \\
\text { adet/gün }\end{array}$ & $P$ value \\
\hline Preeklampsi & $4(\% 5,4)$ & $16(\% 9,8)$ & $3(\% 12,5)$ & 0,432 \\
\hline GDM & $6(\% 8,1)$ & $15(\% 9,2)$ & $1(\% 4,2)$ & 0,704 \\
\hline Kolestaz & 0 & $1(\% 0,6)$ & 0 & \\
\hline $\begin{array}{l}\text { Plasenta İnvaz- } \\
\text { yon Anomalisi }\end{array}$ & 0 & $1(\% 0,6)$ & 0 & \\
\hline Previa & $2(\% 2,7)$ & 0 & 0 & \\
\hline Atoni & $1(\% 1,4)$ & 0 & 0 & \\
\hline EDT & $3(\% 4,1)$ & $12(\% 7,4)$ & $2(\% 8,3)$ & 0,589 \\
\hline EMR & $10(\% 13,5)$ & $21(\% 12,9)$ & $5(\% 20,8)^{*}$ & 0,572 \\
\hline PPROM & $2(\% 2,7)$ & $7(\% 4,3)$ & $3(\% 12,5)^{*}$ & 0,132 \\
\hline $\begin{array}{l}\text { Oligohidram- } \\
\text { nios }\end{array}$ & $4(\% 5,4)$ & $13(\% 8)$ & $4(\% 16,7)$ & 0,211 \\
\hline Polihidramnios & 0 & $7(\% 4,3)$ & 0 & \\
\hline Gün aşımı & $4(\% 5,4)$ & $8(\% 4,9)$ & $1(\% 4,2)$ & 0,969 \\
\hline $\begin{array}{l}\text { Düşük Doğum } \\
\text { Ağırlığı }\end{array}$ & $2(\% 2,7)$ & $24(\% 14,7)$ & $14(\% 58,3)$ & $0,0001^{*}$ \\
\hline $\begin{array}{l}\text { Fetal gelişme } \\
\text { kısıtlılığı }\end{array}$ & $1(\% 1,4)$ & $13(\% 8)$ & $2(\% 8,3)$ & 0,128 \\
\hline $\begin{array}{l}\text { Fetal distress } \\
\text { nedeniyle } \\
\text { sezaryen }\end{array}$ & $5(\% 6,8)$ & $12(\% 7,4)$ & $2(\% 8,3)$ & 0,965 \\
\hline Primer sezaryen & $16(\% 21,6)$ & $30(\% 18,4$ & $5(\% 20,8)$ & 0,834 \\
\hline $\begin{array}{c}\text { Sigara Kullanım } \\
\text { Adedi }\end{array}$ & $\begin{array}{l}\text { Sigara } \leq 5 \\
\text { adet/gün }\end{array}$ & $\begin{array}{l}\text { Sigara } 5 \text { - } \\
15 \text { adet/ } \\
\text { gün }\end{array}$ & $\begin{array}{l}\text { Sigara }>15 \\
\text { adet/gün }\end{array}$ & $P$ value \\
\hline \multicolumn{5}{|l|}{ Doğum Şekli } \\
\hline Sezaryen & $37(\% 50)$ & $77(\% 47,2)$ & $10(\% 41,7)$ & \multirow{2}{*}{0,772} \\
\hline NSD & $37(\% 50)$ & $86(\% 52,8)$ & $14(\% 58,3)$ & \\
\hline Dekolman & $1(\% 1,4)$ & 0 & 0 & \\
\hline YDYBÜ Yatış & $2(\% 2,7)$ & $18(\% 11)$ & $6(\% 25)$ & 0,005 \\
\hline
\end{tabular}

GDM: Gestasyonel diyabetes mellitus, EDT: Erken doğum tehditi, EMR: Erken membran ruptürü, PPROM: preterm prematur ruptur of membran, NSD: Nor mal spontan doğum, YDYBÜ: Yenidogan yoğun bakım ünitesi. 


\section{TARTIŞMA}

Gebelikte sigara maruziyetinin maternal ve fetal çoklu advers etkilerle ilişkili olduğu iyi bilinmektedir (13). Çoğu zaman gebe kadınlar gebelikte sigara içiminin olumsuz sağlik sonuçlarına yol açtığının farkındadırlar; ancak çoğu zaman bu bilgiler gebe kadınları sigarayı bırakmaya motive etmekte yetersiz kalabilmektedir. Bu nedenledir ki hamilelik sırasında sigarayı azaltma işlemi hamilelikte tamamen bırakma işleminden daha olasıdır (14).

Halk sağllğ 1 düzeyinde bir popülasyonun doğum ağırlığındaki küçük bir azalma bile yenidoğanlar için uzun süreli sonuçlar doğurabilir. Dolayısıyla akla şöyle bir soru gelmektedir; maternal ve fetal sonuçlar ile ilişkili "güvenli” bir sigara içme oranı var midır?

Biz de çalışmamızda buradan yola çıkarak gebelikte sigarayı bırakamamış ancak farklı dozlarda sigara kullanan anne adaylarında günlük sigara içim miktarı ile olumsuz maternal ve fetal sonuçlar arasındaki ilişkiyi araştırmayı amaçladık.

Spracklen ve arkadaşları yaptıkları çalışmada maternal sigara içimi ile preeklampsi arasında ilişki bulamamışlar; ancak preeklamptik olup sigara içen gebelerden doğan yenidoğanların non-preeklamptik ve sigara içmeyen gebelerin yenidoğanlarına göre daha küçük olduğu bildirilmiştir (15). Newman ve arkadaşları sigara içiminin primigravid gebeler arasında diğer maternal faktörlerden bağımsız olarak düşük preeklampsi oranları ile birlikte olduğunu bildirmişlerdir (16). Biz ise çalışmamızda gebeliginde sigara kullanan kadınlarda preeklampsi sıklığını hiç sigara kullanmayan hastalara göre daha yüksek oranda saptadık. Ancak günlük sigara kullanım miktarı ile preeklampsi arasında bir ilişki saptamadik.

Shobeiri ve arkadaşlarının meta-analizinde gebelikte sigara kullanımının dekolman plasenta ve plasenta previa riskini anlamlı olarak artırdı $\breve{g}_{1}$ bildirilmiştir (17). Hatta Shobeiri ve arkadaşları gebelikte sigara içimini plasenta previa için bir prediktör olarak belirlemişlerdir. Bizim çalışmamızda plasenta previa ve dekolman plasenta ile gebelikte sigara içimi arasında bir ilișki görülmedi. Sigara kullanan gebeler arasında da sigara kullanım miktarı ile plasenta previa ve dekolman plasenta arasında bir ilişki saptanmadi.

Gebelikte sigara içimi intrauterin büyümeyi ve yenidoğanın doğum ağırlığını etkileyebilir. Tütünün en önemli bileşeni olan nikotin plasentada maternal kandan \%15 daha yüksek bir konsantrasyonda bulunmaktadır. Nikotin, maternal katekolamin salınımını indükleyerek uterin vazokonstriksiyona neden olur. Üstelik maternal sigara içimi umblikal arterlerin karboksihemoglobin seviyelerini arttırır ve bu da fetal hipoksi ile sonuçlanmaktadır (18). Ayrıca anne adayının sigara içmesi leptin konsantrasyonunu azaltarak da doğum ağırlığını azaltabilmektedir (19). Bernstein ve arkadaşları üçüncü trimester maternal sigara içiminin doğum ağırlığ 1 için gestasyonel yaş hesabından sonra en güçlü prediktör olduğunu bildirmişlerdir (20). Bu çalışmada üçüncü trimesterde günlük içilen her bir sigaranın bebeğin doğum ağırlığında $27 \mathrm{~g}$ azalmaya katkıda bulunduğu tahmin edildiği bildirilmiştir. England ve arkadaşları üçüncü trimesterde sigara içilmesinin doğum ağırlığını keskin bir șekilde düşürdüğünü ve bu etkinin günde $>8$ sigaraya eşit olduğunu saptamışlardır (21).

Ko ve arkadaşlarının yaptıkları çalışmada yenidoğanın doğum ağırlığı ile annenin gebelikte içtiği günlük sigara adedi arasında ters korelasyon olduğu bildirilmiş; bu çalışmada günde $>20$ sigara içen annelerin çocuklarının, annenin sigara içtiği gebelik trimesterinden bağımsız olarak, en fazla düşük doğum ağırlığına maruz kaldığ 1 bildirilmiştir (22). Berlin ve arkadaşlarının çalışmasında da gebelikte sigaranın dozuna bağlı olarak doğum ağırlığındaki değişim değerlendirilmiş ve günde $0-5$ adet sigara içenlerde doğum ağırlığındaki azalmanın sigaranın adedi günde $>5$ üzerine çıktığında kademeli olarak arttığ 1 görülmüştür (14). Biz de çalışmamızda sigara içen gebelerde içmeyenlere göre anlamlı oranda yüksek düşük doğum ağırlığı saptadık. Sigara içme oranı arttıkça doğum ağırlığ düşmekte idi. Bu düşüş günlük $>15$ adet sigaraya çıktığında bu oranın $\% 58$ 'e ulaştı̆g görüldü.

Gebelikte sigara içimi FGR ve preterm doğum için de önemli bir risk faktörü olarak bildirilmiş olup yapılan çalışmalarda sigara içenler arasında FGR için odds oran 12.42 ; preterm doğum için 1.41 olarak bulmuştur $(23,24)$. 20 prospektif çalışmanın değerlendirildiği bir meta-analizde gebeliğinde her gün sigara içenlerde preterm doğum riskinde \%27 oranında bir artış olduğunu bildirilmiştir (25). Ko ve arkadaşlarının bir çalışmasında gebelikte sigara içiminin düşük doğum ağırlığı insidansını arttırdığ 1 ve bebeklerin preterm doğumundan sorumlu olduğu gösterilmiştir (22).

Bizim çalışmamızda maternal sigara içenlerde FGR oranı anlamlı yüksek bulunurken; preterm eylem ile maternal sigara kullanımı arasında ilişki saptanmad. Fetal gelişim kısıtlılığ gelişiminde doza bağımlı bir cevap görülmedi. Orta içici bir anne adayı ile ağır içici anne adayında aynı oranda FGR izlendi. Çalışmamızda maternal sigara içimi ile preterm doğum arasında ilişki saptamadık. Preterm doğumun maternal sigara içiminden bağımsız olarak dekolman plasenta ve plasenta previa ile ilişkisi bilinen bir durumdur. Maternal sigara içimi ile preterm doğum ilişkisi saptamamamız yukarıda bahsettimiz olası plasental komplikasyonları beklenenden daha az görmemizi açıklayabilir. Horta ve arkadaşlarının yaptıkları çalışmada maternal aktif sigara içiciliği ile preterm doğum arasında bir ilişki saptanmaz iken; FGR ve düşük doğum ağırlığı arasında güçlü bir ilişki saptanmıştır (26). Horta ve arkadaşları sigaranın bebekte düşük doğum ağırlığ 1 ve / veya FGR olmadığı sürece preterm doğumları etkilemediğini $(\mathrm{OR}=0.80)$ şayet eşlik eden FGR yok ise maternal sigara içiminin preterm doğum için risk faktörü olmadığını rapor etmişlerdir. Chiolero ve arkadaşları maternal sigara içimi günlük $>10$ adet ise 
bunun düşük doğum ağırlığı, SGA ve preterm doğum ile ilişkili olduğunu; ancak sigara içimi günlük 1-9 adet ise bunun düşük doğum ağırlığı ve SGA ile ilişkili olup preterm doğum ile ilişkili olmadığ bildirilmiştir (27). Blatt ve arkadaşlarının 927,424 doğumu analiz ettikleri çalışmada; yenidoğan yoğun bakıma yatış sıklığ 1 sigara içmeyen gebelerde 34,300 (\%4.9), gebeliği boyunca sigara içen gebelerde 8,298 (\%6.3) olarak bildirilmiștir ve bu fark istatistiksel olarak anlamlı bulunmuştur (28). Biz de çalışmamızda yenidoğanın yoğun bakıma yatıș sıklığını sigara içmeyen gebelerde $50(\% 4.9)$ gebeliği boyunca sigara içen gebelerde 26 (\%10) bulduk. Bu fark istatistiksel olarak anlamlı idi. Hafif içicilikten ağır içiciliğe geçildikçe diğer bir deyişle gebelikte içilen sigara adedi günlük 5 ten 15 'in üzerine çıktığında yenidoğanın yoğun bakıma yatma sıklığ1 $\% 2.7$ ' den $\% 25$ ' lere ç1kmaktadır.

Sonuç olarak; biz çalışmamızda gebelikte aktif sigara içen kadınlarda sigara içmeyen gebelere göre preeklampsi, EMR, PPROM, düşük doğum ağırlığ1, FGR, intrauterin fetal kayıp ve NICU başvuru oranlarını daha yüksek bulduk. Ancak günlük kullanılan sigara miktarı ile sadece düşük doğum ağırlığı ve NICU başvuru oranları arasında ilişkili saptadık. Sigara içen bir gebeden doğacak çocuğun nikotinin akut dönem zararlı etkileri yanı sıra çocukluk çağı kronik dönemdeki zararlı etkilerinden de kaçınmamız gerekir. $\mathrm{Bu}$ nedenle sigaranın hiç içilmemesi eğer içiliyorsa gebe kalır kalmaz sigarayı bırakması yönünde desteklenmesi önemlidir.

Sigaranın doz-yanıt ilişkisi değerlendirildiğinde düşük doğum ağırlığı ve NICU' ya başvuru açısından en kötü sonuçlar ağır içicilerde olmaktadır. Dolayısıyla rutin prenatal takiplerde sigarayı birakmayı başaramayan ya da birakmak istemeyen gebelere en azından doz azaltılması yönünde bilgilendirme yapılması fetal zararı minumuma düşürecektir.

\section{KA Y N A KLAR}

1- $\quad$ Committee on Health Care for Underserved Women. Committee opinion number 503: tobacco use and women's health. Obstet Gynecol.2011;118(3):746-50.

2- $\quad$ Balkaya N.A. Vural G. Eroğlu K. Gebelikte Belirlenen Risk Faktörlerinin Anne ve Bebek Sağlı̆̆ Açısından Ortaya Çıkardı̆̆ Sorunların İncelenmesi. Düzce Üniversitesi Sağllk Bilimleri Enstitüsü Dergisi, 2014;4(1): 6-16.

3- Abel EL. Smoking during pregnancy: a review of effects on growth and development of the offspring. Human Biology 1980;52(4):593-625.

4- Bouyer J, Coste J, Shojaei T, Pouly JL, Fernandez H, Gerbaud L, Job-Spira N. Risk factors of ectopic pregnancy: a comprehensive analysis based on a large case-control population based study in France. Am J Epidemol 2003;157(3):185-94.

5- Walsh RA Effects of maternal smoking on adverse pregnancy outcomes: examination of the criteria of causation. Hum Biol. 1994;66(6):1059-92.

6- $\quad$ Andres RL The association of cigarette smoking with placenta previa and abruptio placentae. Semin Perinatol. 1996;20(2):154-9.

7- $\quad$ Agrawal A, Scherrer JF, Grant JD, Sartor CE, Pergadia ML Duncan AE, Madden PA, Haber JR, Jacob T, Bucholz KK, Xian H. The effects of maternal smoking during pregnancy on offspring outcomes. Prev Med. 2010;50(1-2):13-8.
8- Högberg L,Cnattingius S. The influence of maternal smoking habits on the risk of subsequent stillbirth: is there a causal relation? BJOG 2007;114(6): 699-704.

9- $\quad$ Sopori M. Effects of cigarette smokes on the immune system. Nat Rev Immunol 2002;2(5):372-377.

10- Hafström O, Milerad J, Sandberg KL, Sundell HW. Cardiorespiratory effects of nicotine exposure during development. Respir Physiol Neurobiol. 2005; 149(1-3):325-41.

11- Riedel C, Schönberger K, Yang S, Koshy G, Chen YC, Gopinath $B$ et al. Parental smoking and childhood obesity: higher effect estimates for maternal smoking in pregnancy compared with paternal smoking: a meta-analysis. Int J Epidemiol. 2014;43(5):1593-606.

12- Virtanen HE, Sadov S, Toppari J. Prenatal exposure to smoking and male reproductive health. Curr Opin Endocrinol Diabetes Obes. $2012 ; 19(3): 228-32$

13- Huang SH, Weng KP, Huang SM, Liou HH, Wang CC, Ou SF, Lin CC, Chien KJ, Lin CC, Wu MT. The effects of maternal smoking exposure during pregnancy on postnatal outcomes: A cross sectional study. J Chin Med Assoc 2017;80(12):796-802.

14- Berlin I, Golmard JL, Jacob N, Tanguy ML, Heishman SJ. Cigarette Smoking During Pregnancy: Do Complete Abstinence and Low Level Cigarette Smoking Have Similar Impact on Birth Weight? Nicotine Tob Res. 2017;19(5):518-524.

15- Spracklen CN, Ryckman KK, Harland K, Saftlas AF. Effects of smoking and preeclampsia on birth weight for gestational age. J Matern Fetal Neonat Med 2015;28(6):679-684.

16- Newman MG, Lindsay MK, Graves W. Cigarette smoking and pre-eclampsia: their association and effects on clinical outcomes. J Matern Fetal Neonat Med 2001;10(3):166-170.

17- Shobeiri F, Jenabi E. Smoking and placenta previa: a meta-analysis. J Matern Fetal Neonat Med 2017; 30(24):2985-2990.

18- Lambers DS, Clark KE. The maternal and fetal physiologic effects of nicotine. Semin Perinatol 1996;20(2):115-126.

19- Mantzoros CS, Varvarigou A, Kaklamani VG, Beratis NG, Flier $J S$. Effect of birth weight and maternal smoking on cord blood leptin concentrations of full-term and preterm newborns. J Clin Endocrinol Metab. 1997;82(9):2856-61.

20- Bernstein IM, Mongeon JA, Badger GJ, Solomon L, Heil SH, Higgins ST. Maternal smoking and its association with birth weight. Obstet Gynecol. 2005;106(5 pt.1):986-991.

21- England LJ, Kendrick JS, Wilson HG, Merritt RK, Gargiullo $P M$, Zahniser SC. Effects of smoking reduction during pregnancy on the birth weight of term infants. Am J Epidemiol 2001;154(8):694-701.

22- Ko TJ, Tsai LY, Chu LC, Yeh SJ, Leung C, Chen CY, Chou HC, Tsao PN, Chen PC, Hsieh WS. Parental smoking during pregnancy and its association with low birth weight, small for gestational age, and preterm birth offspring: a birth cohort study. Pediatr Neonatol 2014;55(1):20-27.

23- Kramer MS. Determinants of low birthweight: methodological assessment and metaanalysis. Bulletin of the World Health Organization 1987; 65(5):663-737.

24- Berkowitz GS, Papiernik E. Epidemiology of preterm birth. Epidemiologic Reviews 1993;15(2):414-443.

25- Shah NR, Bracken MB. A systematic review and metaanalysis of prospective studies on the association between maternal cigarette smoking and preterm delivery. Am J Obstet Gynecol 2000;182(2):465-472.

26- Horta BL, Victora CG, Menezes AM, Halpern R, Barros FC. Low birthweight, preterm births and intrauterine growth retardation in relation to maternal smoking. Paediatr Perinat Epidemiol 1997;11(2):140151.

27- Chiolero A, Bovet P, Paccaud F. Association between maternal smoking and low birth weight in Switzerland: the EDEN study. Swiss Med Wkly. 2005;135(35-36):525-530.

28- Blatt K, Moore E, Chen A, Van HookJ, DeFranco EA. Association of reported trimester-specific smoking cessation with fetal growth restriction. Obstet Gynecol. 2015;125(6):1452-1459. 